DR PASWACH WIRIYAKIJJA (Orcid ID : 0000-0002-2340-517X)

DR STEFANO FEDELE (Orcid ID : 0000-0001-9006-9412)

Article type : Original Article

\title{
Validation of the HADS and PSS-10 and a cross-sectional study of psychological status in patients with recurrent aphthous stomatitis
}

Paswach Wiriyakijja1, 2*, Stephen Porter ${ }^{1}$, Stefano Fedele ${ }^{1,3}$, Tim Hodgson ${ }^{4}$, Roddy

McMillan $^{4}$, Martina Shephard ${ }^{4}$, Richeal Ni Riordain ${ }^{1,5}$

${ }^{1}$ UCL Eastman Dental Institute, London, United Kingdom

${ }^{2}$ Department of Oral Medicine, Faculty of Dentistry, Chulalongkorn University, Bangkok, Thailand

${ }_{3}^{3}$ NIHR University College London Hospitals Biomedical Research Centre, London, United Kingdom

${ }^{4}$ Eastman Dental Hospital, UCLH Foundation NHS Trust London, London, United Kingdom

${ }^{5}$ Department of Oral Medicine, Cork University Dental School and Hospital, Cork, Ireland.

${ }^{*}$ Corresponding author.

E-mail address: paswach.w@gmail.com

Running title: Psychological status in RAS

Key words: Recurrent aphthous stomatitis; Hospital anxiety and depression scale;

Perceived stress scale; Factor analysis; Anxiety; Depression

This article has been accepted for publication and undergone full peer review but has not been through the copyediting, typesetting, pagination and proofreading process, which may lead to differences between this version and the Version of Record. Please cite this article as doi: $\underline{10.1111 / J O P .12991}$

This article is protected by copyright. All rights reserved 


\section{ABSTRACT}

Objectives: To validate the Hospital Anxiety and Depression Scale (HADS) and the 10item Perceived Stress Scale (PSS-10) for use in clinical studies of recurrent aphthous stomatitis (RAS) and to provide cross-sectional assessment of anxiety, depressive, distress symptoms and perceived stress in patients with RAS.

Methods: Validity and reliability of the HADS and PSS-10 were evaluated in 120 individuals with RAS through confirmatory factor analysis and calculation of Cronbach's alpha and omega coefficients. The prevalence of comorbid anxiety, depression, distress and moderate-to-high perceived stress, as well as their association with demographics and clinical factors, was assessed through cut-off scores of the HADS and PSS-10 and bivariate analyses respectively.

Results: A bi-factor model, with all items loading onto general factor with two group factors, provides the best fit to the HADS and PSS-10 data of this RAS cohort. While omega values suggested adequate reliability of total score of both scales, relatively low ranges of coefficient omega hierarchical limit utility of their subscale scores. The prevalence of anxiety, depressive, distress symptoms and moderate-to-high perceived stress was $42.5 \%, 18.33 \%, 28.33 \%$ and $71.67 \%$ respectively. Ethnicity, alcohol consumption, disease comorbidities, clinical type of RAS, ulcer size, pain and RAS disease activity were found to be associated with negative psychological symptoms.

Conclusion: The HADS and PSS-10 are valid and reliable as general scales of psychological distress and stress in patients with RAS. Significant mental burden among RAS patients makes the use of these validated instruments a sensible and prudent practice for psychological assessment of this patient group. 


\section{Introduction}

Recurrent aphthous stomatitis (RAS) is arguably the most common chronic ulcerative condition of the oral mucosa. The recurrent mucosal ulceration of RAS can be notably painful and have a negative impact on psychological well-being and quality of life of affected individuals ${ }^{1}$. The onset of RAS is often reported during childhood or adolescence $^{2}$, with ulceration lasting from a few days (RAS minor) to several weeks (RAS major). The frequency of oral ulceration development is highly variable and ranges from multiple new ulcers a week to a few episodes a year ${ }^{2}$. Although previous studies have suggested that psychological factors such as stress and anxiety may be associated with the clinical manifestations of RAS in some affected individuals ${ }^{3,4}$, the nature and determinants of this association remain unclear. In addition, little is known regarding the validity and reliability of the self-assessment psychological scales that have been employed in previous studies in this patient population ${ }^{5}$, which raises concerns regarding the appropriateness of these tools in exploring the psychological factors associated with RAS, as well as the accuracy of available results.

The Hospital Anxiety and Depression Scale (HADS) was developed as a brief screening tool for detecting symptoms of anxiety and depression in a non-psychiatric hospital settings ${ }^{6}$. The 10 -item Perceived Stress Scale (PSS-10) is a self-assessment scale developed to measure perceived psychological stress over the past 30 days $^{7}$. Both the HADS and PSS-10 have been extensively used across various settings including clinical RAS research ${ }^{8}$. Despite having been validated in various medical conditions, validity and reliability of both HADS and PSS-10 have yet to be fully investigated in in patients with RAS. It remains therefore unclear whether these scales are structurally valid and reliable for use in this patient population.

The primary objective of the present study was to validate HADS and PSS-10 in a cohort of patients with RAS by examining their structural validity and internal consistency reliability in this patient group. The secondary objective was to assess the prevalence of anxiety, depression, distress and perceived stress in the same group of individuals with 
RAS. Furthermore the association between psychological factors (anxiety, depression, distress and perceived stress), demographics and clinical factors was studied

\section{Methods}

\section{Study design}

This is a cross-sectional, secondary analysis of data from the Determination of Minimal Important Different and Patient Acceptable Symptom State of Patient Reported Outcome Measures in Immunologically mediated Oral Mucosal Diseases (MEAN-IT) study, which was approved by the London - Queen Square Research Ethics Committee (REC reference 17/LO/1825).

\section{Participants}

The study participants included 120 patients diagnosed with RAS attending review appointments at the Oral Medicine clinic of the UCLH Eastman Dental Hospital, London, United Kingdom, between January 2018 and May 2019. The eligibility criteria are listed in Table 1. The participant recruitment was based on a convenience sampling. All potentially eligible participants attending the above mentioned Oral Medicine clinics between January 2018 and May 2019 were approached and invited to participate (conducted by PW).

\section{Sample size calculation}

The sample size was in accordance with the recommendation from the COnsensusbased Standards for the selection of health Measurement Instruments (COSMIN) Risk of Bias checklist ${ }^{9}$, which stipulates that a sample size for a factor analysis study should include at least 100 and more than 7 times the number of items of the outcome measures examined (at least 98 and 70 for factor analysis of the HADS and PSS-10, respectively). 


\section{Procedure}

Disease activity of RAS was evaluated by taking history of each participant (conducted by PW), and specific information about oral ulcers over the past three months was recorded. The activity score was calculated based on the standardized Ulcer Severity Score (USS) ${ }^{10}$. Types of RAS were recorded based upon clinical appearance and behavior of RAS into 3 groups: minor RAS (shallow small ulcers $(<1 \mathrm{~cm})$, usually last $7-10$ days), major RAS (deeper and larger ulcers $(\geq 1 \mathrm{~cm}$ ), lasting several weeks, which may heal with scar formation) and herpetiform RAS (few millimeter ulcers, usually $>10$ ulcers, last 7-10 days $)^{11}$. Participants were then asked to complete the demographic form and a set of patient-reported questionnaires including the numerical rating scale (NRS) for pain, the HADS and the PSS-10. The information regarding the age at symptom onset, disease duration (time since symptom onset), past medical history, social history, and treatment of RAS was obtained from the review of electronic patient record. The present study was reported in accordance with the Strengthening the Reporting of Observational Studies in Epidemiology (STROBE) guidelines ${ }^{12}$ (Appendix).

\section{Outcomes}

The outcome for primary objective (validation study) was evidence supporting structural validity and internal consistency reliability of the HADS and PSS-10 for use in patients with RAS. For structural validity, values of the fit indices were assessed against predefined standard to confirm whether the data of patients with RAS fit the underlying structure of the studied scales. For internal consistency reliability, reliability coefficients were calculated and compared with acceptable quality criteria.

The outcomes for the secondary objective (cross-sectional study) were as follows: (i) prevalence of psychological symptoms including anxiety, depression, distress and stress as measured by the HADS and PSS-10 in individuals with RAS; (ii) Bivariate analyses of potential associated factors of psychological symptoms including demographics and clinical factors. 


\section{Outcome measures}

The Hospital Anxiety and Depression Scale (HADS) is a brief 14-item, 0-3 Likert-type scale with seven questions (HADS-A) assessing anxiety symptoms, and the other seven (HADS-D) assessing depressive symptoms over one week recall period. Subscale HADS scores of 8 or over indicate the presence of anxiety or depressive symptoms ${ }^{8}$, and the total score (HADS-T) from the sum scores of HADS-A and HADS-D of 15 or over indicate the presence of psychological distress ${ }^{13}$.

10-item Perceived Stress Scale (PSS-10) is a 10-item, 5-point Likert-type scale examining participant's level of perceived stress over the last month. Four items of the PSS-10 (item $4,5,7,8$ ) are positively stated items and require reverse coding. PSS-10 scores of 14 or above are indicative of moderate-to-high level of perceived stress ${ }^{14}$.

The Ulcer Severity Score (USS) is a validated RAS-specific scoring system for monitoring the severity of recurrent oral ulcers ${ }^{10}$. Six RAS-related characteristics over the preceding three months including average number of the ulcers, average ulcer size, average ulcer duration, ulcer-free period, affected oral sites, and ulcer-related pain were evaluated to generate the RAS parameter scores of the USS. A total USS score is the summation of all six parameters scores with the maximum total score of 80 .

The Numerical Rating Scale (NRS) for pain estimates severity of oral pain currently experienced by a patient on a whole number scale of 0-10 (11-point scale $)^{15}$.

\section{Data analysis}

Statistical analyses were carried out using STATA version 15.1 (StataCorp, College Station, TX, U.S.A.) and MPlus version 8.2 (Muthén \& Muthén, 2015). Preliminary item analyses were performed to examine median, interquartile range (IQR) and skewness of 
each item in the HADS and PSS-10 ${ }^{16}$. Descriptive statistics for demographic and RASrelated characteristics were summarized using frequencies, percentages, median and interquartile range (IQR) as appropriate.

\section{Validity and reliability of the HADS and PSS-10}

For structural validity testing, confirmatory factor analysis (CFA) were performed. Three HADS and PSS-10 models including one-factor, two-factor and bi-factor model were tested (Figure 1). Bi-factor model allows all the items to load on a general factor reflecting scale unidimensionality, and in addition, onto specific group factors indicating multidimensionality of the scale. Acceptability of model fit was assessed by the use of following fit indices including: root mean square of error approximation (RMSEA), standardized root mean squared residual (SRMR), comparative fit index (CFI) and Tucker-Lewis index (TLI). The RMSEA and SRMR values closer to 0 indicate better fit, with values below 0.08 and 0.05 indicating acceptable and good fit, respectively. The CFI and TLI values greater than 0.95 are considered acceptable ${ }^{17}$.

Cronbach's alpha coefficients were computed to assess internal consistency reliability of both total and subscale scores of the HADS and PSS-10 based upon the best-fit model from the CFA results. Cronbach's alpha $(\alpha)$ of at least 0.70 was considered acceptable 16,18. For the bi-factor models, two additional variance-based reliability indices, including omega coefficient $(\omega)$ and coefficient omega hierarchical $(\omega-h)$, were also calculated. For a comparison with previous study, a cross-sectional analysis of psychological profile of patients with RAS were demonstrated based upon the originally proposed structure of both scales.

\section{Cross-sectional analyses of psychological symptoms in patients with RAS}

Participants were dichotomized by the presence/absence of anxiety, depressive, emotional distress symptoms and moderate-to-high perceived stress using the following cut-off scores of self-report instruments: 8 for the HADS-A, 8 for the HADS-D, 15 for the 
HADS-T and 14 for the PSS-10 respectively. To identify factors related to psychological symptoms in patients with RAS, subgroup bivariate analysis were conducted using the chi-square or Fisher's exact tests for categorical variables, while Mann-Whitney $U$ test or independent sample t-test were performed for continuous variables as appropriate. A pvalue of less than 0.05 was considered statistical significance.

\section{Results}

\section{Descriptive item analyses}

The descriptive item statistics for the HADS and PSS-10 were shown in Table 2. No data of the HADS and PSS-10 were missing, indicating good feasibility of in the present study. Skewness values of all items were generally acceptable (range between -1 and 1) except three HADS-D items, which were marginally high (up to 1.44).

\section{Structural validity}

The fit indices for the original two-factor and one-factor model of the HADS suggested that both models were less than a good fit for use in patients with RAS (Table 3). The bifactor model of HADS fit the RAS data reasonably well, with all goodness-of-fit statistics fell within acceptable (RMSEA) and good (SRMR, CFI, TLI) model fit. As for the PSS-10, the results from the CFA exhibited an approximately equal fit of both two-factor and bifactor models to the RAS data. Comparing the CFI value of the two PSS-10 models, the value for the bi-factor model just reached the threshold for good model fit $(\mathrm{CFI}=0.95)$, indicating marginally superior of this model to the two-factor model of the PSS-10 in this RAS cohort.

\section{Reliability}

The internal consistency reliability for the total and subscale scores of the HADS and PSS-10 were acceptable to good (Cronbach's a range $=0.76-0.89$; see also Table 4). The values of $\omega$ coefficients of subscale and total scores were high, varying from 0.86 to 
0.92 for the HADS, and from 0.82 to 0.93 for the PSS-10. In contrast, The values of $\omega-h$, which estimates scale reliability with the effects of all other factors removed, for each subscale of the HADS and PSS-10 were found to be considerably low, indicating low reliability of subscale scores of both instruments.

\section{Descriptive characteristics of participants}

The median age of all 120 RAS participants was 42.03 years (IQR $=33.22-53.58$ years), and $71(59.17 \%)$ were female. The median age since the first RAS episode was 19.25 years, with disease duration varying from 1 year to 58 years (median $=16.89$ years). Minor RAS was the most prevalent clinical variant of RAS, accounted for $85 \%$ of participants, followed by major (11\%) and herpetiform types $(4 \%)$. Detailed demographic and disease characteristics of the study cohort are summarised in Table 5.

\section{Prevalence and factors related to the presence of psychological symptoms in patients with RAS}

The prevalence of anxiety, depressive symptoms, emotional distress and moderate-tohigh perceived stress in participants with RAS were $42.5 \%, 18.33 \%, 28.33 \%$ and $71.67 \%$, respectively. Significant factors associated with the presence of these psychological symptoms in RAS participants were as follows; ethnicity, non-alcoholic drinkers, at least two disease comorbidities, types of RAS, ulcer size $\geq 1 \mathrm{~cm}$, ulcer pain based upon the USS-pain and NRS for pain and disease activity based upon total USS. The detailed subgroup analysis of the association between demographic and clinical factors and the presence of psychological symptoms in the present sample are shown in Table 5.

\section{Discussion}

The present study examines validity and reliability of the HADS and PSS-10 in patients with RAS. Results from the factor analysis demonstrated that a bi-factor model, with all 
items loading onto general factor with two group factors, provides the best fit to the HADS and PSS-10 data of patients with RAS than the originally proposed model. These findings were consistent with recent validation studies of both scales in various medical diagnoses $^{19,20}$, and demonstrated evidence of structural validity of both measures in a sample of RAS.

To further test the appropriateness of using subscale and total scores of both measures, reliability coefficients of the bi-factor model were evaluated. Although values of omega coefficient $(\omega)$ were in an acceptable range in both scales, values of coefficient $\omega$-h of the group factors were relatively low when compared with coefficient $\omega$-h of the general factors. Coefficient $\omega$-h estimates actual reliability of each latent factor (both general and group) once the effects of other factors are controlled. Consequently, the present findings supported the summation of total scores of both the HADS and PSS-10, while the interpretation of subscale scores as reliable indices of group constructs (i.e. anxiety and depression in the HADS) is limited. Considering the psychometric evidence of the present study, the HADS and PSS-10 should be used as unidimensional scales of overall emotional distress and perceived stress with the use of total scores only in patients with RAS.

Several studies have found that patients with RAS had higher level of anxiety ${ }^{21,22}$, depression $^{23}$, distress ${ }^{24}$ and psychological stress ${ }^{25}$ when compared to healthy individuals while some studies did not find the difference between two groups ${ }^{4,26}$. The prevalence of anxiety symptoms in the present RAS cohort was higher than that reported in a previous study of Croatian patients (42.5\% versus $24.47 \%$ ) whereas the figures for depressive symptoms was much lower $(18.3 \% \text { versus } 47.06 \%)^{27}$. Notably, over two-thirds of participants in this study had moderate-to-high stress level over the past month. This was in agreement with a previous Brazilian study ${ }^{25}$. Based upon these, it appeared that there was a significant mental health burden among patients with RAS. 
The present study suggested that certain subgroups of patients with RAS might be at greater risk of having comorbid psychological symptoms when compared to other RAS subgroups. A significantly higher proportion of patients from non-white ethnic groups in this RAS cohort had comorbid anxiety and emotional distress than those from white ethnicity. These findings were consistent with the most recent Adult Psychiatric Morbidity Survey (2014) in England. A significantly higher number of non-alcohol drinkers with RAS in this study have depressive symptoms when compared to those who consume alcohol. This finding matched several studies in different conditions including oral lichen planus ${ }^{28}$, which found the increased risk of having depressive symptoms among non-alcohol drinkers. One possible explanation of this association might be a result of certain social confounding factors. In general, mid-range alcohol drinkers may be more culturally and socially well-adjusted, and these traits might indirectly prevent them from having depression ${ }^{29}$.

Regarding RAS-related clinical characteristics, the present results found that those with average larger ulcer size $(\geq 1 \mathrm{~cm})$ appeared to report symptoms of anxiety, distress and moderate-to-high stress more than those having smaller ulcer size. Correspondingly, greater number of patients with major RAS reported having psychological symptoms compared to patients with minor RAS. This finding might be attributed to the fact that major RAS ulcers are larger, deeper, more painful, longer lasting and associated with significant functional impairment ${ }^{1}$, resulting in more psychological distress and stress in comparison with minor RAS ulcers. In terms of oral pain, a previous study found positive associations between pain intensity and level of psychological symptoms in patients with RAS $^{27}$. Oral symptoms and associated functional impairment could initiate or exacerbate psychological symptoms, and in turn, the presence of a mental health disorder may increase awareness and lower tolerance of physical symptoms and, consequently, cause further psychological symptoms.

Overall disease activity of RAS was found to be associated with only moderate-to-high level of stress and not with other psychological symptoms. Experiencing stressful life 
events was found to be associated with roughly a three-fold increase in the likelihood of having new RAS episode, and an increase in stress severity appeared not to have an impact on the progression and frequency of recurrence of the RAS episodes ${ }^{3}$. The present analyses confirmed the findings of this previous work and did not find any association between psychological factors and either duration of RAS episodes or ulcerfree periods.

Based upon the present findings, there is some association between psychological symptoms and patient's perceived disease activity. In light of this, management of RAS should include psychological assessment using validated instruments to identify patients requiring additional psychological assessment. Depending on the severity of identified psychological distress or stress, it is the clinician's responsibility to make onward referral of patients for appropriate management from the general practitioner, psychologist, or psychiatrist. The recognition and treatment of these psychological problems could help improving the perceived disease activity and quality of life of patients with RAS.

A number of caveats need to be addressed in the present study. The prevalence figures of comorbid psychological illnesses in this study were estimated by the use of screening instruments, and therefore the findings need to be interpreted cautiously. The present study did not evaluate socioeconomic factors, which could be potential confounding factors of the present results. The use of a cross-sectional design limits its ability to draw a valid conclusion whether psychological symptoms was pre-existent to RAS diagnosis or a consequence of having RAS. The generalisability of the study results may be limited as study participants were recruited in one tertiary oral medicine unit, and thus the results might not be transferrable to the real-world RAS population.

\section{Conclusions}

The HADS and PSS-10 are valid and reliable as general measures of psychological distress and perceived stress in patients with RAS. Based upon the findings, there is a 
significant mental burden among patients with RAS, which makes screening for psychological symptoms a prudent and sensible practice in this patient group. The knowledge of demographic and clinical characteristics related to psychological symptoms in patients with RAS may facilitate clinicians in providing better holistic care and may contribute to improve the quality of life of patients with this condition.

\section{Author contributions}

Paswach Wiriyakijja and Richeal Ni Riordain designed the study. Paswach Wiriyakijja collected data from OLP patients, performed the statistical analyses reported in the study and wrote manuscript. Richeal Ni Riordain, Martina Shephard, Roddy McMillan, Tim Hodgson, Stefano Fedele and Stephen Porter edited and contributed to the manuscript.

\section{Conflict of interest}

None to declare.

\section{Acknowledgement}

Paswach Wiriyakijja would like to thank Dr. Emma Hayes, Dr. Priya Thakrar, Dr. Krupali Patel, Dr. Barbara Carey, Dr. Carolina Venda Nova, Dr. Craig Whitelaw and Dr. Thomas Saunsbury for their substantial help and supports towards the recruitment process of the study and for reviewing and editing the manuscript. Paswach Wiriyakijja received a PhD Scholarship from the Faculty of Dentistry, Chulalongkorn University, Bangkok, Thailand. Stefano Fedele received funding from the National Institute for Health Research University College London Hospitals Biomedical Research Centre. The MEAN-IT study received service support funding from the National Institute for Health Research University College London Hospitals Biomedical Research Centre and the NIHR Clinical Research Network Portfolio. 


\section{References}

1. Akintoye SO, Greenberg MS. Recurrent aphthous stomatitis. Dent Clin North Am. 2014;58(2):281297.

2. Jurge S, Kuffer R, Scully C, Porter SR. Mucosal disease series. Number VI. Recurrent aphthous stomatitis. Oral Dis. 2006;12(1):1-21.

3. Huling LB, Baccaglini L, Choquette L, Feinn RS, Lalla RV. Effect of stressful life events on the onset and duration of recurrent aphthous stomatitis. J Oral Pathol Med. 2012;41(2):149-152.

4. Picek P, Buljan D, Rogulj AA, et al. Psychological status and recurrent aphthous ulceration. Coll Antropol. 2012;36(1):157-159.

5. Wiriyakijja P, Fedele S, Porter S, Mercadante V, Ni Riordain R. Patient-reported outcome measures in recurrent aphthous stomatitis: A critical assessment of quality properties. Oral Dis. 2017;23(8):1168-1179.

6. Zigmond AS, Snaith RP. The hospital anxiety and depression scale. Acta Psychiatr Scand. 1983;67(6):361-370.

7. Cohen S, Tyrrell DA, Smith AP. Negative life events, perceived stress, negative affect, and susceptibility to the common cold. J Pers Soc Psychol. 1993;64(1):131-140.

8. Bjelland I, Dahl AA, Haug TT, Neckelmann D. The validity of the Hospital Anxiety and Depression Scale. An updated literature review. J Psychosom Res. 2002;52(2):69-77.

9. Mokkink LB, de Vet HCW, Prinsen CAC, et al. COSMIN Risk of Bias checklist for systematic reviews of Patient-Reported Outcome Measures. Qual Life Res. 2018;27(5):1171-1179.

10. Tappuni AR, Kovacevic T, Shirlaw PJ, Challacombe SJ. Clinical assessment of disease severity in recurrent aphthous stomatitis. J Oral Pathol Med. 2013;42(8):635-641.

11. Scully C, Porter S. Oral mucosal disease: recurrent aphthous stomatitis. Br J Oral Maxillofac Surg. 2008;46(3):198-206.

12. von Elm E, Altman DG, Egger M, Pocock SJ, Gotzsche PC, Vandenbroucke JP. Strengthening the Reporting of Observational Studies in Epidemiology (STROBE) statement: guidelines for reporting observational studies. Bmj. 2007;335(7624):806-808.

13. Schellekens MPJ, van den Hurk DGM, Prins JB, Molema J, van der Drift MA, Speckens AEM. The suitability of the Hospital Anxiety and Depression Scale, Distress Thermometer and other instruments to screen for psychiatric disorders in both lung cancer patients and their partners. Journal of affective disorders. 2016;203:176-183.

This article is protected by copyright. All rights reserved 
14. Alharbi H, Alshehry A. Perceived stress and coping strategies among ICU nurses in government tertiary hospitals in Saudi Arabia: a cross-sectional study. Ann Saudi Med. 2019;39(1):48-55.

15. Hawker GA, Mian S, Kendzerska T, French M. Measures of adult pain: Visual Analog Scale for Pain (VAS Pain), Numeric Rating Scale for Pain (NRS Pain), McGill Pain Questionnaire (MPQ), ShortForm McGill Pain Questionnaire (SF-MPQ), Chronic Pain Grade Scale (CPGS), Short Form-36 Bodily Pain Scale (SF-36 BPS), and Measure of Intermittent and Constant Osteoarthritis Pain (ICOAP). Arthritis Care Res (Hoboken). 2011;63 Suppl 11:S240-252.

16. Terwee $\mathrm{CB}$, Bot SD, de Boer MR, et al. Quality criteria were proposed for measurement properties of health status questionnaires. J Clin Epidemiol. 2007;60(1):34-42.

17. Hu L-t, Bentler PM. Cutoff criteria for fit indexes in covariance structure analysis: Conventional criteria versus new alternatives. Structural Equation Modeling. 1999;6(1):1-55.

18. Mokkink LB, Terwee CB, Patrick DL, et al. The COSMIN study reached international consensus on taxonomy, terminology, and definitions of measurement properties for health-related patientreported outcomes. J Clin Epidemiol. 2010;63(7):737-745.

19. Burns A, Hofer S, Curry P, Sexton E, Doyle F. Revisiting the dimensionality of the Hospital Anxiety and Depression Scale in an international sample of patients with ischaemic heart disease. $J$ Psychosom Res. 2014;77(2):116-121.

20. Reis D, Lehr D, Heber E, Ebert DD. The German Version of the Perceived Stress Scale (PSS-10): Evaluation of Dimensionality, Validity, and Measurement Invariance With Exploratory and Confirmatory Bifactor Modeling. Assessment. 2019;26(7):1246-1259.

21. Cardoso JA, Dos Santos Junior AA, Nunes ML, de Figueiredo MA, Cherubini K, Salum FG. Salivary Alpha-Amylase Enzyme, Psychological Disorders, and Life Quality in Patients with Recurrent Aphthous Stomatitis. Int J Dent. 2017;2017:5269856.

22. Al-Omiri MK, Karasneh J, Lynch E. Psychological profiles in patients with recurrent aphthous ulcers. Int J Oral Maxillofac Surg. 2012;41(3):384-388.

23. Polat C, Duzer S, Ayyildiz H, et al. Association Between Anxiety, Depression, and Salivary Cortisol Levels in Patients with Recurrent Aphthous Stomatitis. Turk Arch Otorhinolaryngol. 2018;56(3):166-169.

24. Tabolli S, Bergamo F, Alessandroni L, Di Pietro C, Sampogna F, Abeni D. Quality of life and psychological problems of patients with oral mucosal disease in dermatological practice. Dermatology. 2009;218(4):314-320.

25. Gallo Cde B, Mimura MA, Sugaya NN. Psychological stress and recurrent aphthous stomatitis. Clinics (Sao Paulo). 2009;64(7):645-648.

This article is protected by copyright. All rights reserved 
26. Zwiri AM. Anxiety, Depression and Quality of Life among Patients with Recurrent Aphthous Ulcers. J Contemp Dent Pract. 2015;16(2):112-117.

27. Gavic L, Cigic L, Biocina Lukenda D, Gruden V, Gruden Pokupec JS. The role of anxiety, depression, and psychological stress on the clinical status of recurrent aphthous stomatitis and oral lichen planus. J Oral Pathol Med. 2014;43(6):410-417.

28. Wiriyakijja P, Porter S, Fedele S, et al. Validation of the HADS and PSS-10 and psychological status in patients with oral lichen planus. Oral Dis. 2019.

29. Skogen JC, Harvey SB, Henderson M, Stordal E, Mykletun A. Anxiety and depression among abstainers and low-level alcohol consumers. The Nord-Trondelag Health Study. Addiction. 2009;104(9):1519-1529.

This article is protected by copyright. All rights reserved 


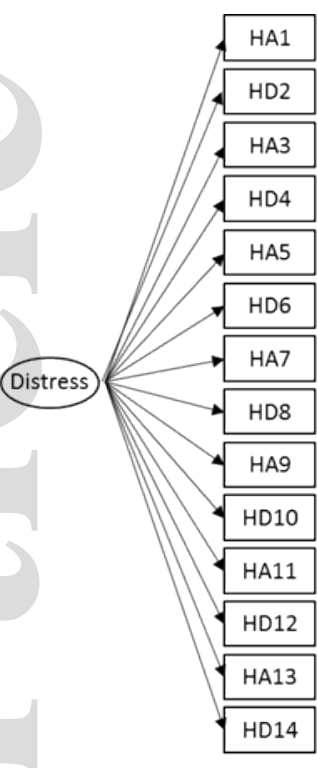

HADS 1-factor model

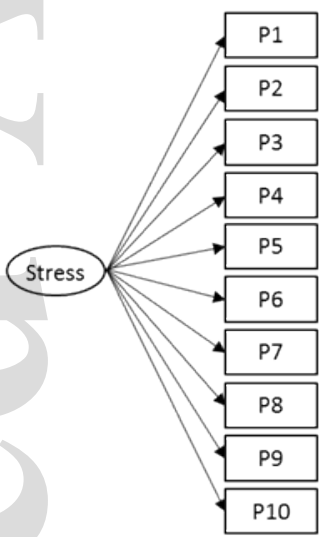

PSS 1-factor model

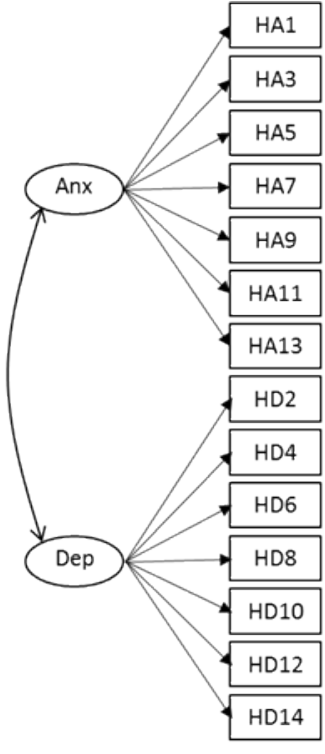

HADS 2-factor model

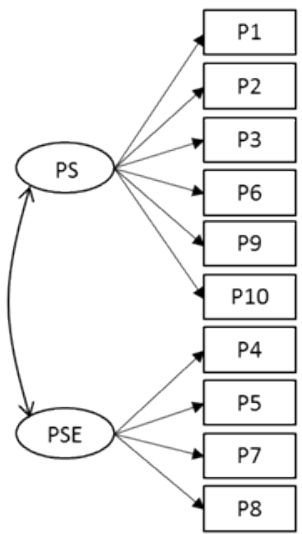

PSS 2-factor model

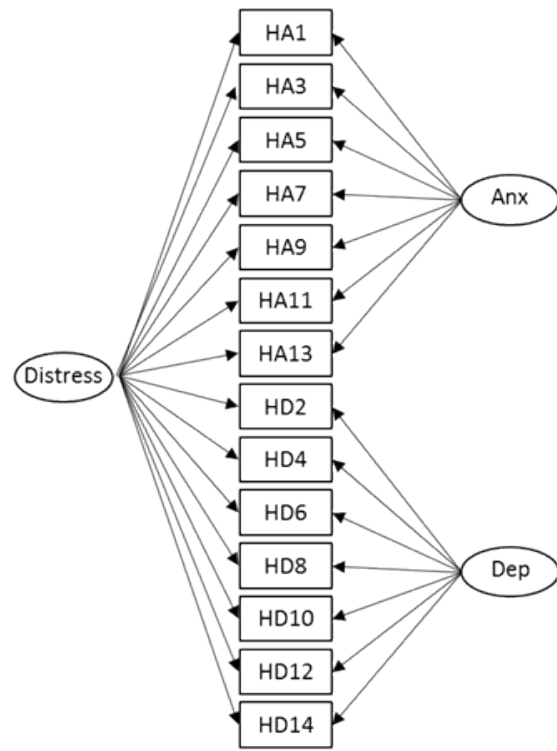

HADS bifactor model

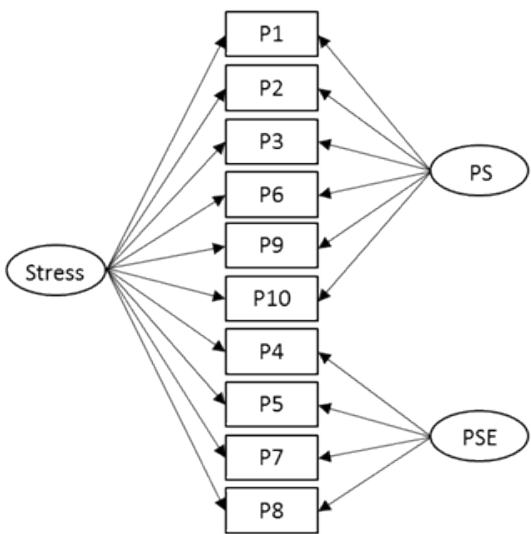

PSS bifactor model

Figure 1 Structural models of the HADS and PSS-10 applied in the confirmatory factor analyses using the OLP population (Abbreviation: Anx = anxiety subscale, Dep = depression subscale, $\mathrm{PS}=$ perceived stress subscale, $\mathrm{PSE}=$ perceived self-efficacy subscale)

Table 1 Study eligibility criteria

This article is protected by copyright. All rights reserved 
Inclusion criteria

- Aged 18 years or older

- Having recurrent oral ulceration (ulcer episodes of at least twice a year)

- Able to understand and complete questionnaires

- Agree to participate and provide written informed consent
Exclusion criteria

- Having RAS-like ulcerations associated with systemic disorders such as Behcet's disease, Sweet syndrome, Ulcerative colitis, Crohn's disease, Celiac disease, autoinflammatory syndromes, or haematological abnormalities (severe anaemia, cyclic or chronic neutropenia)

- Having coexisting chronic neuropathic orofacial pain, such as post-traumatic trigeminal neuropathic pain, persistent idiopathic facial pain or burning mouth syndrome - Severe systemic disease (ASA 3 or more) and/or some psychiatric conditions which might affect the participation of the study such as schizophrenia 
Table 2 Descriptive statistics for each of the HADS and PSS-10 item

\begin{tabular}{|c|c|c|c|c|c|c|c|c|}
\hline \multirow{2}{*}{ Items } & \multirow{2}{*}{$\begin{array}{l}\text { med } \\
(\mathrm{IQR})\end{array}$} & \multirow{2}{*}{$\begin{array}{l}\text { mean } \\
\text { (SD) }\end{array}$} & \multicolumn{5}{|c|}{ score distribution (\%) } & \multirow{2}{*}{ skewness } \\
\hline & & & 0 & 1 & 2 & 3 & 4 & \\
\hline \multicolumn{9}{|l|}{ HADS-anxiety } \\
\hline HA1 Tense-wound up & $1(1,2)$ & $\begin{array}{c}1.38 \\
(0.69)\end{array}$ & $9(7.5)$ & $\begin{array}{c}62 \\
(51.67)\end{array}$ & $\begin{array}{c}44 \\
(36.67)\end{array}$ & $5(4.17)$ & - & 0.14 \\
\hline HA3 Frightened feelings & $1(0,2)$ & $\begin{array}{c}0.88 \\
(0.95)\end{array}$ & $\begin{array}{c}53 \\
(44.17)\end{array}$ & $36(30)$ & $\begin{array}{c}23 \\
(19.17)\end{array}$ & $8(6.67)$ & - & 0.71 \\
\hline HA5 Worrying thought & $1(1,2)$ & $\begin{array}{c}1.18 \\
(0.92)\end{array}$ & $\begin{array}{c}29 \\
(24.17)\end{array}$ & $54(45)$ & $24(20)$ & $\begin{array}{c}13 \\
(10.83)\end{array}$ & - & 0.49 \\
\hline HA7 At ease-relaxed & $1(0,2)$ & $\begin{array}{c}0.99 \\
(0.75)\end{array}$ & $\begin{array}{c}33 \\
(27.5)\end{array}$ & $\begin{array}{c}56 \\
(46.67)\end{array}$ & $30(25)$ & $1(0.83)$ & - & 0.13 \\
\hline $\begin{array}{l}\text { HA9 Butterflies in } \\
\text { stomach }\end{array}$ & $1(0,1)$ & $\begin{array}{c}0.74 \\
(0.74)\end{array}$ & $48(40)$ & $\begin{array}{c}59 \\
(49.17)\end{array}$ & $9(7.5)$ & $4(3.33)$ & - & 0.95 \\
\hline HA11 Restless & $1(1,2)$ & $\begin{array}{c}1.24 \\
(0.86)\end{array}$ & $\begin{array}{c}26 \\
(21.67)\end{array}$ & $\begin{array}{c}46 \\
(38.33)\end{array}$ & $\begin{array}{c}41 \\
(34.17)\end{array}$ & $7(5.83)$ & - & 0.07 \\
\hline HA13 Sudden panic & $1(0,1)$ & $\begin{array}{c}0.84 \\
(0.87)\end{array}$ & $\begin{array}{c}49 \\
(40.83)\end{array}$ & $48(40)$ & $\begin{array}{c}16 \\
(13.33)\end{array}$ & $7(5.83)$ & - & 0.85 \\
\hline \multicolumn{9}{|l|}{ HADS-depression } \\
\hline HD2 Enjoy things & $1(0,1)$ & $\begin{array}{c}0.64 \\
(0.68)\end{array}$ & $\begin{array}{c}57 \\
(47.5)\end{array}$ & $\begin{array}{c}49 \\
(40.83)\end{array}$ & $\begin{array}{c}14 \\
(11.67)\end{array}$ & $0(0)$ & - & 0.59 \\
\hline HD4 Laugh-see funny side & $0(0,1)$ & $\begin{array}{c}0.48 \\
(0.72)\end{array}$ & $\begin{array}{c}77 \\
(64.17)\end{array}$ & $\begin{array}{c}31 \\
(25.83)\end{array}$ & $\begin{array}{c}10 \\
(8.33)\end{array}$ & $2(1.67)$ & - & 1.44 \\
\hline HD6 Cheerful & $1(0,1)$ & $\begin{array}{c}0.68 \\
(0.67)\end{array}$ & $\begin{array}{c}50 \\
(41.67)\end{array}$ & $60(50)$ & $8(6.67)$ & $2(1.67)$ & - & 0.8 \\
\hline HD8 Slowed down & $1(1,2)$ & $\begin{array}{c}1.12 \\
(0.85)\end{array}$ & $\begin{array}{c}28 \\
(23.33)\end{array}$ & $\begin{array}{c}59 \\
(49.17)\end{array}$ & $24(20)$ & $9(7.5)$ & - & 0.51 \\
\hline HD10 Lost interest & $0(0,1)$ & $\begin{array}{c}0.62 \\
(0.79)\end{array}$ & $\begin{array}{c}67 \\
(55.83)\end{array}$ & $\begin{array}{c}34 \\
(28.33)\end{array}$ & $\begin{array}{c}17 \\
(14.17)\end{array}$ & $2(1.67)$ & - & 1 \\
\hline HD12 Excitement & $0(0,1)$ & $\begin{array}{c}0.61 \\
(0.76)\end{array}$ & $\begin{array}{c}65 \\
(54.17)\end{array}$ & $\begin{array}{c}39 \\
(32.5)\end{array}$ & $\begin{array}{c}14 \\
(11.67)\end{array}$ & $2(1.67)$ & - & 1.02 \\
\hline HD14 Enjoy leisures & $0(0,1)$ & $\begin{array}{c}0.38 \\
(0.57)\end{array}$ & $\begin{array}{c}79 \\
(65.83)\end{array}$ & $36(30)$ & $5(4.17)$ & $0(0)$ & - & 1.16 \\
\hline \multicolumn{9}{|l|}{ PSS-10 } \\
\hline P1 Upset & $2(1,3)$ & $\begin{array}{c}1.93 \\
(1.06)\end{array}$ & $\begin{array}{c}14 \\
(11.67)\end{array}$ & $\begin{array}{c}21 \\
(17.5)\end{array}$ & $\begin{array}{c}52 \\
(43.33)\end{array}$ & $\begin{array}{c}25 \\
(20.83)\end{array}$ & $8(6.67)$ & -0.12 \\
\hline P2 Life-uncontrollable & $2(1,2)$ & $\begin{array}{c}1.63 \\
(1.13)\end{array}$ & $\begin{array}{c}23 \\
(19.17)\end{array}$ & $\begin{array}{c}29 \\
(24.17)\end{array}$ & $\begin{array}{c}45 \\
(37.5)\end{array}$ & $\begin{array}{c}15 \\
(12.50)\end{array}$ & $8(6.67)$ & 0.23 \\
\hline P3 Nervous-stressed & $2(2,3)$ & $\begin{array}{c}2.43 \\
(0.99)\end{array}$ & $4(3.33)$ & $\begin{array}{c}13 \\
(10.83)\end{array}$ & $\begin{array}{c}49 \\
(40.83)\end{array}$ & $\begin{array}{c}35 \\
(29.17)\end{array}$ & $\begin{array}{c}19 \\
(15.83)\end{array}$ & -0.18 \\
\hline P4 Ability to handle & $1(1,2)$ & 1.33 & 27 & 46 & 31 & 13 & $3(2.5)$ & 0.5 \\
\hline
\end{tabular}




\begin{tabular}{|c|c|c|c|c|c|c|c|c|}
\hline problems & & $(1.02)$ & $(22.5)$ & (38.33) & $(25.83)$ & (10.83) & & \\
\hline \multirow[t]{2}{*}{ P5 Things going your way } & $1(1,2)$ & 1.55 & $12(10)$ & 50 & 41 & 14 & $3(2.5)$ & 0.41 \\
\hline & & $(0.92)$ & & (41.67) & (34.17) & (11.67) & & \\
\hline \multirow[t]{2}{*}{ P6 Unable to cope } & $2(1,2)$ & 1.71 & 19 & 32 & 43 & 17 & $9(7.5)$ & 0.24 \\
\hline & & $(1.13)$ & (15.83) & (26.67) & $(35.83)$ & (14.17) & & \\
\hline \multirow[t]{2}{*}{ P7 Control irritations } & $1(1,2)$ & 1.57 & 14 & 47 & $42(35)$ & 11 & $6(5)$ & 0.53 \\
\hline & & $(0.99)$ & (11.67) & (39.17) & & $(9.17)$ & & \\
\hline \multirow[t]{2}{*}{ P8 On top of things } & $1(1,2)$ & 1.47 & 10 & 61 & 35 & 11 & $3(2.5)$ & 0.72 \\
\hline & & $(0.87)$ & $(8.33)$ & $(50.83)$ & (29.17) & $(9.17)$ & & \\
\hline \multirow[t]{2}{*}{ P9 Angry } & $2(1,3)$ & 1.95 & 11 & 27 & $48(40)$ & 25 & $9(7.5)$ & 0.01 \\
\hline & & $(1.05)$ & $(9.17)$ & $(22.5)$ & & $(20.83)$ & & \\
\hline P10 Difficulties- & $2(1,2)$ & 1.58 & 22 & 35 & 41 & 16 & $6(5)$ & 0.28 \\
\hline overloaded & & (1.09) & (18.33) & (29.17) & (34.17) & (13.33) & & \\
\hline
\end{tabular}

Table 3 Confirmatory factor analysis model fit statistics

\begin{tabular}{lllll}
\hline & RMSEA & SRMR & CFI & TLI \\
\hline HADS & & & & \\
1-factor model & 0.14 & 0.11 & 0.83 & 0.8 \\
2-factor model & 0.1 & 0.09 & 0.91 & 0.89 \\
bifactor model & 0.06 & 0.05 & 0.98 & 0.97 \\
\hline PSS-10 & & & & \\
1-factor model & 0.21 & 0.08 & 0.85 & 0.8 \\
2-factor model & 0.13 & 0.04 & 0.94 & 0.93 \\
bifactor model & 0.14 & 0.04 & 0.95 & 0.92 \\
\hline
\end{tabular}


Table 4 Reliability estimates of overall and subscale scores of the HADS and PSS-10

\begin{tabular}{lccc}
\hline & Cronbach's $\alpha$ & McDonald's $\omega$ & $\omega$-h \\
\hline HADS-total (distress) & 0.852 & 0.92 & 0.729 \\
HADS-anxiety subscale & 0.829 & 0.89 & 0.474 \\
HADS-depression subscale & 0.763 & 0.86 & 0.107 \\
PSS-total (stress) & 0.88 & 0.931 & 0.835 \\
PSS-perceived stress subscale & 0.888 & 0.926 & 0.025 \\
PSS-perceived self-efficacy subscale & 0.762 & 0.819 & 0.444 \\
\hline
\end{tabular}

This article is protected by copyright. All rights reserved 
Table 5 Descriptive statistics of demographics and RAS-related variables of study participants and bivariate analysis of factors associated with the presence of anxiety symptoms, depressive symptoms, psychological distress and moderate-to-high perceived stress in patients with RAS ( $\mathrm{N}=120$ )

\begin{tabular}{|c|c|c|c|c|c|c|c|c|c|c|c|c|c|}
\hline Characteristics & $\begin{array}{l}\text { All subjects } \\
(\mathrm{N}=120)\end{array}$ & $\begin{array}{c}\text { HADS-A<8 } \\
(\mathrm{N}=69,57.5 \%)\end{array}$ & $\begin{array}{c}\text { HADS-A } \geq 8 \\
(\mathrm{~N}=51,42.5 \%)\end{array}$ & $\begin{array}{c}\mathrm{P} \\
\text { value }\end{array}$ & $\begin{array}{c}\text { HADS-D<8 } \\
(\mathrm{N}=98,81.67 \%)\end{array}$ & $\begin{array}{c}\text { HADS-D } \geq 8 \\
(\mathrm{~N}=22,18.33 \%)\end{array}$ & $\begin{array}{c}\mathrm{P} \\
\text { value }\end{array}$ & $\begin{array}{c}\text { HADS- }<15 \\
(\mathrm{~N}=86,71.67 \%)\end{array}$ & $\begin{array}{c}\text { HADS-T } \geq 15 \\
(\mathrm{~N}=34,28.33 \%)\end{array}$ & $\begin{array}{c}\mathrm{P} \\
\text { value }\end{array}$ & $\begin{array}{c}\text { PSS- }-1<14 \\
(\mathrm{~N}=34,28.33 \%)\end{array}$ & $\begin{array}{c}\text { PSS- } \mathrm{T} \geq 14 \\
(\mathrm{~N}=86,71.67 \%)\end{array}$ & $\begin{array}{c}P \\
\text { value }\end{array}$ \\
\hline \multicolumn{14}{|l|}{ Demographics } \\
\hline Age (years): median (IQR) & $\begin{array}{c}42.03 \\
(33.22,53.58)\end{array}$ & $\begin{array}{c}42.01 \\
(34.04,51.42)\end{array}$ & $\begin{array}{c}43.84 \\
(31.06,54.01)\end{array}$ & $0.78^{\mathrm{a}}$ & $\begin{array}{c}41.65 \\
(32.94,52.22)\end{array}$ & $\begin{array}{c}49.40 \\
(35.28,56.37)\end{array}$ & $0.21^{\mathrm{a}}$ & $\begin{array}{c}41.46 \\
(33.14,52.22)\end{array}$ & $\begin{array}{c}47.50 \\
(33.41,54.62)\end{array}$ & $0.47^{\mathrm{a}}$ & $\begin{array}{c}39.07 \\
(33.30,51.02)\end{array}$ & $\begin{array}{c}46.40 \\
(32.94,53.79)\end{array}$ & $0.56^{\mathrm{a}}$ \\
\hline Gender $(n, \%)$ & & & & $0.493^{c}$ & & & $0.994^{\mathrm{C}}$ & & & $0.109^{c}$ & & & $0.383^{\mathrm{C}}$ \\
\hline Female & 71 (59.17) & $39(54.93)$ & $32(45.07)$ & & $58(81.69)$ & $13(18.31)$ & & $47(66.20)$ & $24(33.80)$ & & $18(25.35)$ & $53(74.65)$ & \\
\hline Male & $49(40.83)$ & $30(61.22)$ & 19 (38.78) & & 40 (81.63) & $9(18.37)$ & & 39 (79.59) & $10(20.41)$ & & $16(32.65)$ & $33(67.35)$ & \\
\hline Ethnicity $(n, \%)$ & & & & $0.049^{b}$ & & & $0.117^{b}$ & & & $0.022^{b}$ & & & $0.161^{b}$ \\
\hline White & $93(77.50)$ & $58(62.37)$ & $35(37.63)$ & & 79 (84.95) & $14(15.05)$ & & $72(77.42)$ & $21(22.58)$ & & $31(33.33)$ & $62(66.67)$ & \\
\hline Mixed & $5(4.17)$ & $1(20)$ & $4(80)$ & & $4(80)$ & $1(20)$ & & $2(40)$ & $3(60)$ & & $0(0)$ & $5(100)$ & \\
\hline Asian & $16(13.33)$ & $9(56.25)$ & $7(43.75)$ & & $12(75)$ & $4(25)$ & & $10(62.5)$ & $6(37.5)$ & & $2(12.5)$ & $14(87.5)$ & \\
\hline Black & $6(5)$ & $1(16.67)$ & $5(83.33)$ & & $3(50)$ & $3(50)$ & & $2(33.33)$ & $4(66.67)$ & & $1(16.67)$ & $5(83.33)$ & \\
\hline \multicolumn{14}{|l|}{ Smoking $(n, \%)$} \\
\hline Non-smoker & $99(82.5)$ & $56(56.57)$ & $43(43.43)$ & & $81(81.82)$ & 18 (18.18) & & $71(71.72)$ & $28(28.28)$ & & $29(29.29)$ & $70(70.71)$ & \\
\hline Ever smoker & $21(17.5)$ & $13(61.90)$ & $8(38.10)$ & $0.653^{c}$ & $17(80.95)$ & $4(19.05)$ & $0.926^{C}$ & 15 (71.43) & $6(28.57)$ & $0.979^{C}$ & $5(23.81)$ & 16 (76.19) & $0.613^{c}$ \\
\hline Ex-smoker & $13(10.83)$ & $8(61.54)$ & $5(38.46)$ & $0.94^{\mathrm{b}}$ & $12(92.31)$ & $1(7.69)$ & $0.255^{\mathrm{b}}$ & 11 (84.62) & $2(15.38)$ & $0.284^{b}$ & $4(30.77)$ & $9(69.23)$ & $0.672^{b}$ \\
\hline Current smoker & $8(6.67)$ & $5(62.5)$ & $3(37.5)$ & & $5(62.5)$ & $3(37.5)$ & & $4(50)$ & $4(50)$ & & $1(12.5)$ & $7(87.5)$ & \\
\hline \multicolumn{14}{|l|}{ Alcohol consumption $(n, \%)$} \\
\hline No & $39(32.5)$ & $20(51.28)$ & 19 (48.72) & & $27(69.23)$ & $12(30.77)$ & & $25(64.10)$ & $14(35.90)$ & & $7(17.95)$ & $32(82.05)$ & \\
\hline Yes & $81(67.5)$ & $49(60.49)$ & $32(39.51)$ & $0.339^{\mathrm{C}}$ & $71(87.65)$ & $10(12.35)$ & $0.015^{c}$ & $61(75.31)$ & $20(24.69)$ & $0.202^{\mathrm{C}}$ & $27(33.33)$ & $54(66.67)$ & $0.08^{c}$ \\
\hline$\leq 14$ Units/week & 77 (64.17) & $47(61.04)$ & $30(38.96)$ & $0.535^{b}$ & $68(88.31)$ & $9(11.69)$ & $0.037^{b}$ & $59(76.62)$ & $18(23.38)$ & $0.202^{b}$ & $25(32.47)$ & $52(67.53)$ & $0.142^{b}$ \\
\hline > 14 Units/week & $4(3.33)$ & $2(50)$ & $2(50)$ & & $3(75)$ & $1(25)$ & & $2(50)$ & $2(50)$ & & $2(50)$ & $2(50)$ & \\
\hline
\end{tabular}

This article is protected by copyright. All rights reserved 


\section{Comorbidity (n, \%)}

1 comorbidity

$$
57 \text { (47.5) }
$$

$37(30.83)$

26 (21.67)

$\geq 2$ comobidities

Note: ${ }^{a}$ Mann-Whitney test: ${ }^{b}$ Fisher's exact test; ${ }^{c}$ Chis
$0.682^{\mathrm{C}}$

$0.05^{c}$

$0.074^{\mathrm{C}}$

$0.268^{\mathrm{C}}$

$\begin{array}{ll}48(84.21) & 9(15.79) \\ 33(89.19) & 4(10.81) \\ 17(65.38) & 9(34.62)\end{array}$

44 (77.19)

$28(75.68)$

13 (22.81)

9 (24.32)

14 (53.85)

12 (46.15)
20 (35.09)

9 (24.32)

5 (19.23)
37 (64.91)

28 (75.68)

21 (80.77)

Table 5 Descriptive statistics of demographics and RAS-related variables of study participants and bivariate analysis of factors associated with the presence of anxiety symptoms, depressive symptoms, psychological distress and moderate-to-high perceived stress in patients with RAS ( $\mathrm{N}=120$ ) (cont.)

\begin{tabular}{|c|c|c|c|c|c|c|c|c|c|c|c|c|c|}
\hline Characteristics & $\begin{array}{l}\text { All subjects } \\
(\mathrm{N}=120)\end{array}$ & $\begin{array}{c}\text { HADS-A<8 } \\
(\mathrm{N}=69,57.5 \%)\end{array}$ & $\begin{array}{c}\text { HADS-A } \geq 8 \\
(\mathrm{~N}=51,42.5 \%)\end{array}$ & $\begin{array}{c}\mathrm{P} \\
\text { value }\end{array}$ & $\begin{array}{c}\text { HADS-D }<8 \\
(\mathrm{~N}=98,81.67 \%)\end{array}$ & $\begin{array}{c}\text { HADS-D } \geq 8 \\
(\mathrm{~N}=22,18.33 \%)\end{array}$ & $\begin{array}{c}\mathrm{P} \\
\text { value }\end{array}$ & $\begin{array}{c}\text { HADS- }<15 \\
(\mathrm{~N}=86,71.67 \%)\end{array}$ & $\begin{array}{c}\text { HADS- } \mathrm{T} \geq 15 \\
(\mathrm{~N}=34,28.33 \%)\end{array}$ & $\begin{array}{c}P \\
\text { value }\end{array}$ & $\begin{array}{c}\text { PSS- }<<14 \\
(\mathrm{~N}=34,28.33 \%)\end{array}$ & $\begin{array}{c}\text { PSS-T } \geq 14 \\
(\mathrm{~N}=86,71.67 \%)\end{array}$ & $P$ value \\
\hline \multicolumn{14}{|l|}{ RAS-related variables } \\
\hline Age at onset (years): med (IQR) & $\begin{array}{c}19.25 \\
(10.66,35.36)\end{array}$ & $\begin{array}{c}15.61 \\
(11.33,34.52)\end{array}$ & $\begin{array}{c}19.40 \\
(9.97,38.15)\end{array}$ & $0.69^{\mathrm{a}}$ & $\begin{array}{c}16.22 \\
(9.97,34.52)\end{array}$ & $\begin{array}{c}24.12 \\
(14.54,42.12)\end{array}$ & $0.21^{\mathrm{a}}$ & $\begin{array}{c}16.22 \\
(9.90,34.52)\end{array}$ & $\begin{array}{c}20.47 \\
(12.93,42.12)\end{array}$ & $0.28^{\mathrm{a}}$ & $\begin{array}{c}14.89 \\
(9.90,33.45)\end{array}$ & $\begin{array}{c}19.38 \\
(11.33,36.73)\end{array}$ & $0.34^{\mathrm{a}}$ \\
\hline $\begin{array}{l}\text { Disease duration (years): } \\
\text { median (IQR) }\end{array}$ & $\begin{array}{c}16.89 \\
(7.20,27.70)\end{array}$ & $\begin{array}{c}18.50 \\
(8.54,28.56)\end{array}$ & $\begin{array}{c}15.55 \\
(5.43,26.56)\end{array}$ & $0.69^{\mathrm{a}}$ & $\begin{array}{c}18.73 \\
(7.49,28.56)\end{array}$ & $\begin{array}{c}15.16 \\
(5.43,22.38)\end{array}$ & $0.70^{\mathrm{a}}$ & $\begin{array}{c}18.73 \\
(7.49,28.56)\end{array}$ & $\begin{array}{c}15.16 \\
(5.43,25.43)\end{array}$ & $0.54^{\mathrm{a}}$ & $\begin{array}{c}19 \\
(10.23,26.85)\end{array}$ & $\begin{array}{c}15.47 \\
(5.16,28.56)\end{array}$ & $0.45^{\mathrm{a}}$ \\
\hline \multicolumn{14}{|l|}{ Clinical types ( $n, \%)$} \\
\hline Minor & $102(85)$ & $63(61.76)$ & 39 (38.24) & $0.063^{b}$ & $87(85.29)$ & 15 (14.71) & $0.016^{b}$ & 78 (76.47) & $24(23.53)$ & $0.016^{b}$ & $33(32.35)$ & $69(67.65)$ & $0.082^{b}$ \\
\hline Major & $13(10.83)$ & $4(30.77)$ & $9(69.23)$ & & $9(69.23)$ & $4(30.77)$ & & $6(46.15)$ & $7(53.85)$ & & $1(7.69)$ & $12(92.31)$ & \\
\hline Herpetiform & $5(4.17)$ & $2(40)$ & $3(60)$ & & $2(40)$ & $3(60)$ & & $2(40)$ & $3(60)$ & & $0(0)$ & $5(100)$ & \\
\hline \multicolumn{14}{|l|}{ Ulcer Severity Score (USS) } \\
\hline USS-ulcer size (mm): median (IQR) & $4(2.5,6)$ & $4(2,6)$ & $4(3,6)$ & $0.72^{\mathrm{a}}$ & $4(2,6)$ & $4.5(3,7)$ & $0.328^{\mathrm{a}}$ & $4(2,6)$ & $4(3,7)$ & $0.38^{\mathrm{a}}$ & $3.5(2,6)$ & $4(3,6)$ & $0.58^{\mathrm{a}}$ \\
\hline
\end{tabular}

This article is protected by copyright. All rights reserved 


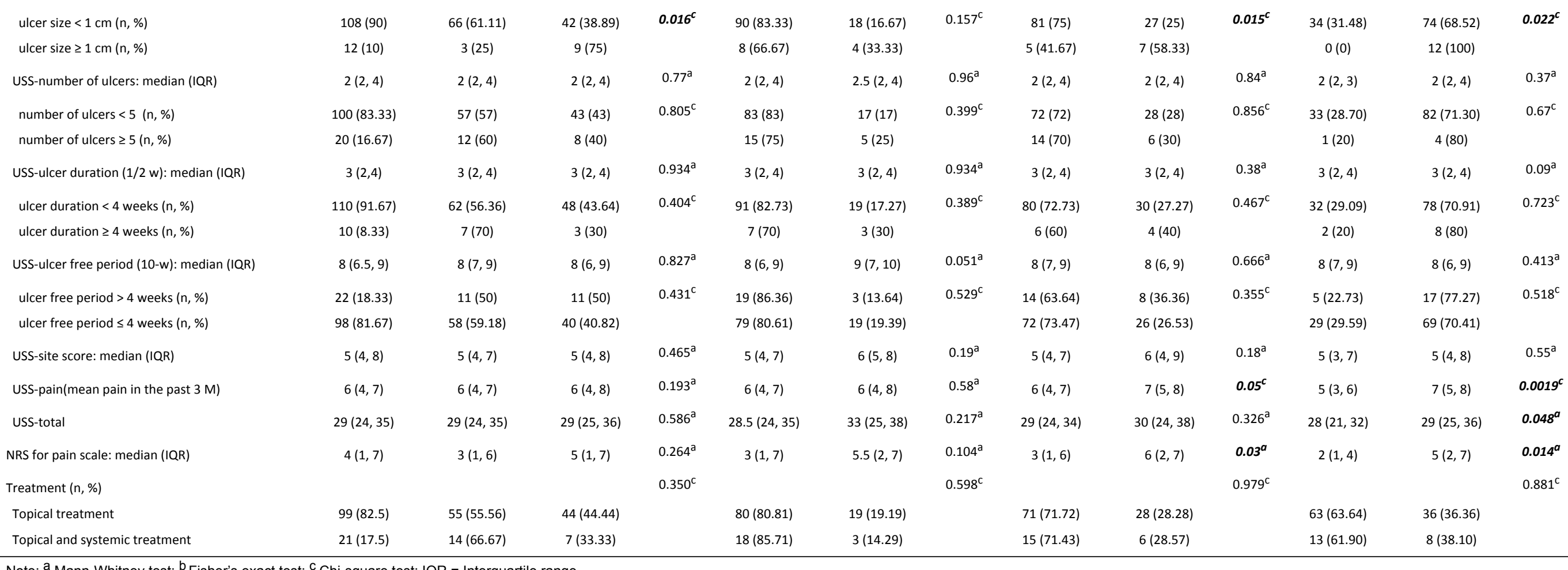

Note: ${ }^{a}$ Mann-Whitney test; ${ }^{b}$ Fisher's exact test; ${ }^{\mathrm{c}}$ Chi-square test; IQR $=$ Interquartile range

This article is protected by copyright. All rights reserved 